\title{
Biodiversity of bacteriophages infecting Lactococcus lactis starter cultures
}

\author{
Joana Oliveira, ${ }^{*}$ Jennifer Mahony, ${ }^{\star} †$ Laurens Hanemaaijer, $\ddagger$ Thijs R. H. M. Kouwen,‡ \\ and Douwe van Sinderen* $\dagger^{1}$ \\ *School of Microbiology, University College Cork, Cork, Ireland \\ †Alimentary Pharmabiotic Centre (APC) Microbiome Institute, University College Cork, Cork, Ireland T12 YT20 \\ fDSM Biotechnology Center, 2613 AX Delft, the Netherlands
}

\begin{abstract}
In the current study, we characterized 137 Lactococcus lactis bacteriophages that had been isolated between 1997 and 2012 from whey samples obtained from industrial facilities located in 16 countries. Multiplex PCR grouping of these 137 phage isolates revealed that the majority (61.31\%) belonged to the 936 group, with the remainder belonging to the P335 and c2 groups (23.36 and $15.33 \%$, respectively). Restriction profile analysis of phage genomic DNA indicated a high degree of genetic diversity within this phage collection. Furthermore, based on a host-range survey of the phage collection using 113 dairy starter strains, we showed that the c2-group isolates exhibited a broader host range than isolates of the 936 and P335 groups.
\end{abstract}

Key words: lactic acid bacteria, lactococcal phage group, whey sample, dairy starter strains

\section{INTRODUCTION}

Bacteriophages or phages (i.e., viruses that infect bacteria) are the most abundant and diverse biological entities present in the earth's biosphere (Garneau and Moineau, 2011; Marco et al., 2012). Ecological niches such as dairy fermentation plants constitute an ideal environment for the propagation and persistence of phages infecting bacterial starter strains, where such infections may cause fermentation issues of varying severity (Marco et al., 2012). Bacterial growth to high cell densities of specific lactic acid bacteria, such as Lactococcus lactis, Streptococcus thermophilus, Leuconostoc spp., and Lactobacillus spp., is required for a successful dairy fermentation, but it also provides a perfect "breeding ground" for phages that are present in the manufacturing environment (Garneau and

Received June 27, 2017.

Accepted September 10, 2017.

${ }^{1}$ Corresponding author: d.vansinderen@ucc.ie
Moineau, 2011). Characterized phages infecting Lc. lactis possess a double-stranded DNA genome and belong to the Caudovirales order, and are members of either the long-tailed Siphoviridae or the short-tailed Podoviridae families (Deveau et al., 2006; Mahony and van Sinderen, 2014). Among the 10 currently recognized lactococcal phage groups, members of the so-called 936, P335, and c2 groups appear to be the most frequently encountered phages in the dairy environment (Deveau et al., 2006). Isolation and enumeration of phages from milk and whey samples is typically performed by plaque assays (Lillehaug, 1997). In recent years, molecular and diagnostic tools have become more commonly used for rapid and reliable detection of these 3 major groups, primarily by means of a multiplex PCR approach (Labrie and Moineau, 2000; del Rio et al., 2007). Several studies have shown that 936-group phages are the most endemic and problematic group of lactococcal phages in fermentation facilities (Kleppen et al., 2011; Mahony et al., 2012; Murphy et al., 2016). Thus, members of this group have been extensively characterized (phenotypically and genetically) so as to improve our understanding of their morphology, interactions with the host, genetic diversity, and sensitivity to biocidal and thermal treatments (Crutz-Le Coq et al., 2002; Dupont et al., 2004; Mahony et al., 2006, 2013; Murphy et al., $2014,2016)$. In contrast to the well-studied 936-group phages, public databases currently hold just 10 complete c2-group genome sequences, which typically exhibit extensive DNA homology (Schouler et al., 1994; Lubbers et al., 1995; Millen and Romero, 2016). Genetic diversity within this group is largely confined to 3 open reading frames ( $\mathrm{ORF}$ ), whose encoded products are believed to be responsible for the observed hostrange differences (Stuer-Lauridsen et al., 2003; Millen and Romero, 2016). Comparative genomic analysis of phages belonging to the P335 group has revealed significant genetic diversity and the absence of a "core" genome; that is, no single gene is conserved among all assigned members of this phage group (Mahony et al., 2014). The genomes of members of the P335 group exhibit extensive mosaicism as a presumed consequence of 
recombination between related phages that may involve virulent and temperate members of this group (Labrie et al., 2008). Despite the implementation of various strategies to control (lactococcal) phages in dairy facilities (such as sanitation, culture rotations, and factory/equipment design), their presence and persistence remain a serious biotechnological problem (Marco et al., 2012). Identified phages are typically propagated on a suitable Lc. lactis host and then characterized using several approaches, including determination of host range, restriction enzyme profiling of phage genomic DNA, and morphological analysis by electron microscopy (Deveau et al., 2006; Szczepanska et al., 2007; Labrie et al., 2008; Mahony et al., 2013; Murphy et al., 2013). Additionally, to identify the host receptor used by certain phages and to enable the development of predictive tools and improved strain rotation strategies, lactococcal strains have been grouped based on the operon that specifies the biosynthetic machinery for the cell wall polysaccharide (CWPS) produced by the lactococcal host (Dupont et al., 2004; Spinelli et al., 2006; Chapot-Chartier et al., 2010; Mahony et al., 2013, 2017; Ainsworth et al., 2014a; Farenc et al., 2014; Murphy et al., 2016). To date, 3 CWPS types have been distinguished (designated types A, B, and C; Mahony et al., 2013), and additional, as-yet uncharacterized, CWPS types are known to exist (collectively designated as the unknown or U type; Ainsworth et al., 2014a).

Here, we report on the isolation and preliminary characterization of 137 lactococcal phages that were obtained from industrial facilities located in various geographical areas. Individual phages were classified as belonging to the 936, c2, or P335 phage groups, followed by host-range determination and host CWPS type identification.

\section{MATERIALS AND METHODS}

\section{Bacterial Strains}

One hundred thirteen industrial Lc. lactis strains were grown overnight at $30^{\circ} \mathrm{C}$ in $10 \%$ reconstituted skim milk and passaged in M17 broth (Oxoid Ltd., Basingstoke, UK) supplemented with $0.5 \%$ glucose (GM17) or lactose (LM17), where relevant. To obtain a pure bacterial culture, a fresh streak from a lactococcal overnight culture was performed on M17 agar (Oxoid Ltd.) supplemented with $0.5 \%$ glucose (GM17) or lactose (LM17), and a single colony was taken for further growth in M17 broth (using conditions as described above) and stocked in $20 \%$ sterile glycerol (Sigma Chemical, St. Louis, MO) at $-20^{\circ} \mathrm{C}$.

\section{Bacteriophage Isolation}

Plaque assays were performed to screen whey samples that had been collected from dairy fermentation plants located in different countries over a period of 19 yr. In this manner, 137 lytic phages were isolated (Supplemental Tables S1, S2, and S3; https://doi.org/ 10.3168/jds.2017-13403) and confirmed using a previously described double agar layer method (Lillehaug, 1997). A single plaque of a particular phage was propagated on an appropriate Lc. lactis host. Briefly, Lc. lactis hosts were grown to an optical density $\left(\mathrm{OD}_{600 \mathrm{~nm}}\right)$ of approximately 0.15 to 0.2 in $10 \mathrm{~mL}$ of GM17 broth supplemented with $10 \mathrm{mM} \mathrm{CaCl}$ (final concentration), followed by the addition of an individual plaque (using a 10- $\mu \mathrm{L}$ inoculation loop; Sarstedt, Nümbrecht, Germany), and incubated at $30^{\circ} \mathrm{C}$ until lysis had occurred. The lysates were then filtered through a $0.45-\mu \mathrm{m}$ filter (Sarstedt) to remove any residual bacterial debris and stored at $4^{\circ} \mathrm{C}$. Using a previously described method (Lillehaug, 1997), plaque assays were performed to determine the phage titer for each isolated phage [typically $10^{8}$ to $10^{9}$ plaque-forming units $(\mathbf{p f u}) / \mathrm{mL}$ ], and phage stocks were maintained as lysates at $4^{\circ} \mathrm{C}$.

\section{Phage DNA Extraction and Restriction Profile Analysis}

Fifty milliliters of GM17 broth was inoculated with a (1\%) fresh overnight Lc. lactis culture and supplemented with $10 \mathrm{mM} \mathrm{CaCl}_{2}$ (final concentration). The Lc. lactis culture was grown until early exponential phase, and $500 \mu \mathrm{L}$ of phage lysate (with a titer of $\sim 10^{8} \mathrm{pfu} / \mathrm{mL}$ ) was added, followed by incubation at $30^{\circ} \mathrm{C}$ until lysis occurred. The resulting phage lysate was filtered using a $0.45-\mu \mathrm{m}$ filter and treated with DNase and RNase to remove residual host chromosomal DNA and RNA, followed by incubation at $37^{\circ} \mathrm{C}$ for $40 \mathrm{~min}$. Polyethylene glycol ( PEG $_{8000}$, Sigma-Aldrich, St. Louis, MO) was added to a final concentration of $10 \%$ followed by incubation at $4^{\circ} \mathrm{C}$ for $16 \mathrm{~h}$. Phage DNA extraction was performed as described previously (Mahony et al., 2013), and enzymatic restriction was performed by digesting phage DNA using EcoRV and EcoRI FastDigest enzymes, as recommended by the manufacturer (Thermo Fisher Scientific, Waltham, MA). The reaction mixture was incubated at $37^{\circ} \mathrm{C}$ for $15 \mathrm{~min}$ and the resulting restriction products were applied to a $1 \%$ agarose gel and visualized by using a UV transilluminator.

\section{Multiplex PCR for Phage Speciation}

Phage genotyping was performed using a previously established multiplex PCR methodology (Labrie and 
Table 1. Multiplex PCR primers ( $F w=$ forward; $R v=$ reverse) for genotypic characterization of phage isolates

\begin{tabular}{llcl}
\hline Primer & Sequence $\left(5^{\prime}\right.$ to $\left.3^{\prime}\right)$ & $\begin{array}{c}\text { Product } \\
\text { size }(\mathrm{bp})\end{array}$ & Reference \\
\hline $936 \mathrm{Fw}$ & TCAATGGAAGACCAAGCGGA & 179 & Labrie and Moineau, 2000 \\
$936 \mathrm{Rv}$ & GTAGGAGACCAACCCAAGCC & 474 & Labrie and Moineau, 2000 \\
c2 Fw & CAGGTGTAAAGTTCGAGAACT & & Labrie and Moineau, 2000 \\
c2 $R v$ & CAGATAATGCACCTGATCA & 682 & \\
P335 Fw & GAAGCTAGGCGAATCAGTAA & & \\
P335 Rv & GATTGCCATTTGCGCTCTGA & & \\
\hline
\end{tabular}

Moineau, 2000), in which 3 sets of primers based on the species-specific regions of the 3 dominant lactococcal phage groups (936, P335, and c2; primers are listed in Table 1) were used. Primers were manufactured by Eurofins MWG (Ebersberg, Germany). Phage DNA extracts were used as a template for the PCR reactions, and the amplification conditions were identical to those described previously (Labrie and Moineau, 2000). Generated PCR products were subjected to electrophoretic examination as described above.

\section{CWPS Typing of Lactococcal Strains by Multiplex PCR}

To determine which particular CWPS type was associated with the corresponding host range of a given phage, a multiplex PCR-based CWPS typing method was used as described previously (Mahony et al., 2013). Primers based on genomic regions specific to the CWPS $\mathrm{A}, \mathrm{B}$, or $\mathrm{C}$ types and a positive control (based on the conserved $r m l B$ gene, which is present in all known CWPS gene clusters) were used to yield products as described in Table 2. The PCR cycles were as follows: $95^{\circ} \mathrm{C}$ for 6 min followed by 31 cycles of $95^{\circ} \mathrm{C}$ for $15 \mathrm{~s}$, $57^{\circ} \mathrm{C}$ for $30 \mathrm{~s}$, and $72^{\circ} \mathrm{C}$ for $1 \mathrm{~min}$, followed by a final extension step at $72^{\circ} \mathrm{C}$ for $7 \mathrm{~min}$.

\section{Phage Host-Range Determination}

Phages isolated in this study were propagated to a high titer $\left(10^{8}\right.$ to $\left.10^{9} \mathrm{pfu} / \mathrm{mL}\right)$ on a suitable sensitive host, and were then used in a host-range survey against a bank of 113 lactococcal strains. Briefly, $10 \mu \mathrm{L}$ of each phage lysate was spotted against the individual members of the lactococcal strain collection via the double layer agar method, as previously described (Lillehaug, 1997), and a host-range analysis was thus performed for all identified phages.

\section{RESULTS AND DISCUSSION}

\section{Prevalence and Geographical Distribution of Phages from Dairy Facilities}

To assess phage prevalence in dairy facilities, an extensive phage identification and phage-host screen was performed, using a large number of whey samples that were individually tested against a collection of 113 industrial lactococcal strains. To the best of our knowledge, this is the largest phage biodiversity screen of dairy facilities across 2 decades involving more than 100,000 whey samples (the original whey sample screens were performed by our collaborators from DSM Biotechnology Center). Whey samples that were posi-

Table 2. Multiplex PCR primers ( $F w=$ forward; $R v=$ reverse) used for the characterization of cell wall polysaccharide (CWPS) type in the Lactococcus lactis hosts ${ }^{1}$

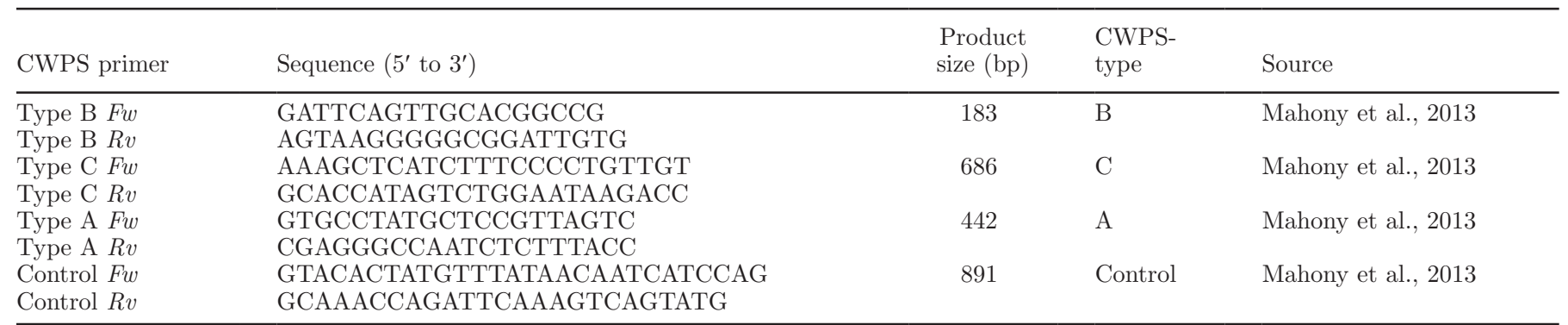

${ }^{1}$ Primers were designed based on conserved and unique regions within the operons of strain UC509.9 for CWPS type A; strain IL1403 for CWPS type B; and strain MG1363 for CWPS type C. 
tive for the presence of phages were further explored for population diversity through the propagation of individual plaque isolates, resulting in a collection of 186 phage isolates. A phage-host survey (details of which are described below) of individually propagated phages resulted in the identification of 137 distinct phage isolates that reliably and lytically propagated on at least one lactococcal strain. These 137 phages represent isolates from whey samples that had been obtained between 1997 and 2012 from dairy plants located in a wide variety of countries, including France, Slovakia, the United States, the United Kingdom, Japan, the Czech Republic, Canada, Austria, Germany, and Spain (Supplemental Tables S1, S2, and S3; https://doi.org/ 10.3168/jds.2017-13403). The lactococcal strains used in this study were predominantly representatives of $L c$. lactis ssp. cremoris $(77 \%)$, with a smaller proportion of Lc. lactis ssp. lactis (19.5\%) and Lc. lactis ssp. lactis biovar diacetylactis (3.5\%) (data not shown).

\section{Grouping Lactococcal Bacteriophages by Multiplex PCR}

Grouping of the phage isolates was performed using an established multiplex PCR approach (Labrie and Moineau, 2000) to determine the relative abundance of 936-, P335-, and c2-group members among the identified phages. In this manner, we showed that among the 137 lactococcal phages isolated in this study, members of the 936 lactococcal phage groups were the most dominant (84/137 isolates; $61.31 \%$ ). The remaining isolated phages belonged to either the P335 group $(32 / 137$ isolates; $23.36 \%)$ or the c2 group (21/137; 15.33\%; Table 3).

The geographical and phage group distribution patterns of these 137 isolated lactococcal phages are shown in Figure 1. A large proportion of the identified phages (38 and 20 out of 137, respectively) were isolated from whey samples derived from factories in the United States and the United Kingdom, and contained representatives of all 3 identified lactococcal phage groups. Whey samples from Iran and Austria appeared to contain only phages belonging to the P335 group, whereas

Table 3. Grouping of newly identified lactococcal bacteriophages by multiplex PCR

\begin{tabular}{lrc}
\hline & \multicolumn{2}{c}{ Phage isolates } \\
\cline { 2 - 3 } Phage & No. & $\%$ \\
\hline 936 & 84 & 59.85 \\
P335 & 32 & 24.82 \\
c2 & 21 & 15.33 \\
Total & 137 & 100 \\
\hline
\end{tabular}

samples from Sweden, Spain, Italy, and Finland exclusively contained 936-group phages (Figure 1). It was not possible to link the geographical location of the isolated phages and their overall relative distribution because detailed information regarding the number and location of screened whey samples was not available. Furthermore, for 23 of the lytic phages (out of 137 isolates; Figure 1) identified in this study, no information was available on the source of the corresponding whey sample. Therefore, to assess possible phylogeographical links and relative phage distribution, more detailed information regarding the isolation of whey samples (source, starter culture information, origin, and distribution) is required for future biodiversity studies of dairy phages.

\section{Phage Host-Range Determination}

As mentioned above, the host range of the 137 lactococcal phages identified in this study was determined by spot assays against a collection of 113 lactococcal strains (using a previously described method; Lillehaug, 1997). The resulting host-range data, which represent 15,481 potential phage-host interactions, revealed that 93 lactococcal strains (from our collection of 113) were sensitive to at least one phage, and 20 lactococcal strains were shown to exhibit complete resistance against all phages assessed in this study (Figure 2A and Table $5)$. This resistance may be due to the activity of antiphage systems, which are known to be abundant among lactococcal strains (Emond et al., 1997; Deng et al., 2000; Mills et al., 2006; Labrie et al., 2010; Ainsworth et al., 2014b). Equally, it is possible that phage receptors on the cell surface are absent, shielded, or altered in these strains, providing insensitivity to the phages present in the current collection (Labrie et al., 2010). A more detailed examination of the phage-host survey data (Supplemental Tables S1, S2, and S3; https:// doi.org/10.3168/jds.2017-13403) showed that c2-group isolates exhibited the broadest host range, with 42 lactococcal strains susceptible (Figure 2C), where 21 c2-group phages (out of 137 phages) were able to infect an average of 9.09 hosts (Table 4). The P335 phages of our collection were capable of infecting an average of 4.47 hosts (Figure 2D and Table 4), and the 936-group phages infected an average of just 2.48 hosts (Figure 2B and Table 4). Five strains in the collection were shown to be susceptible to representative members of all 3 phage groups (Table $5 ; 4.43 \%$ ).

\section{CWPS Typing of Lactococcal Strains}

To assess the preference of lactococcal phages for hosts with a particular CWPS type, the CWPS type 


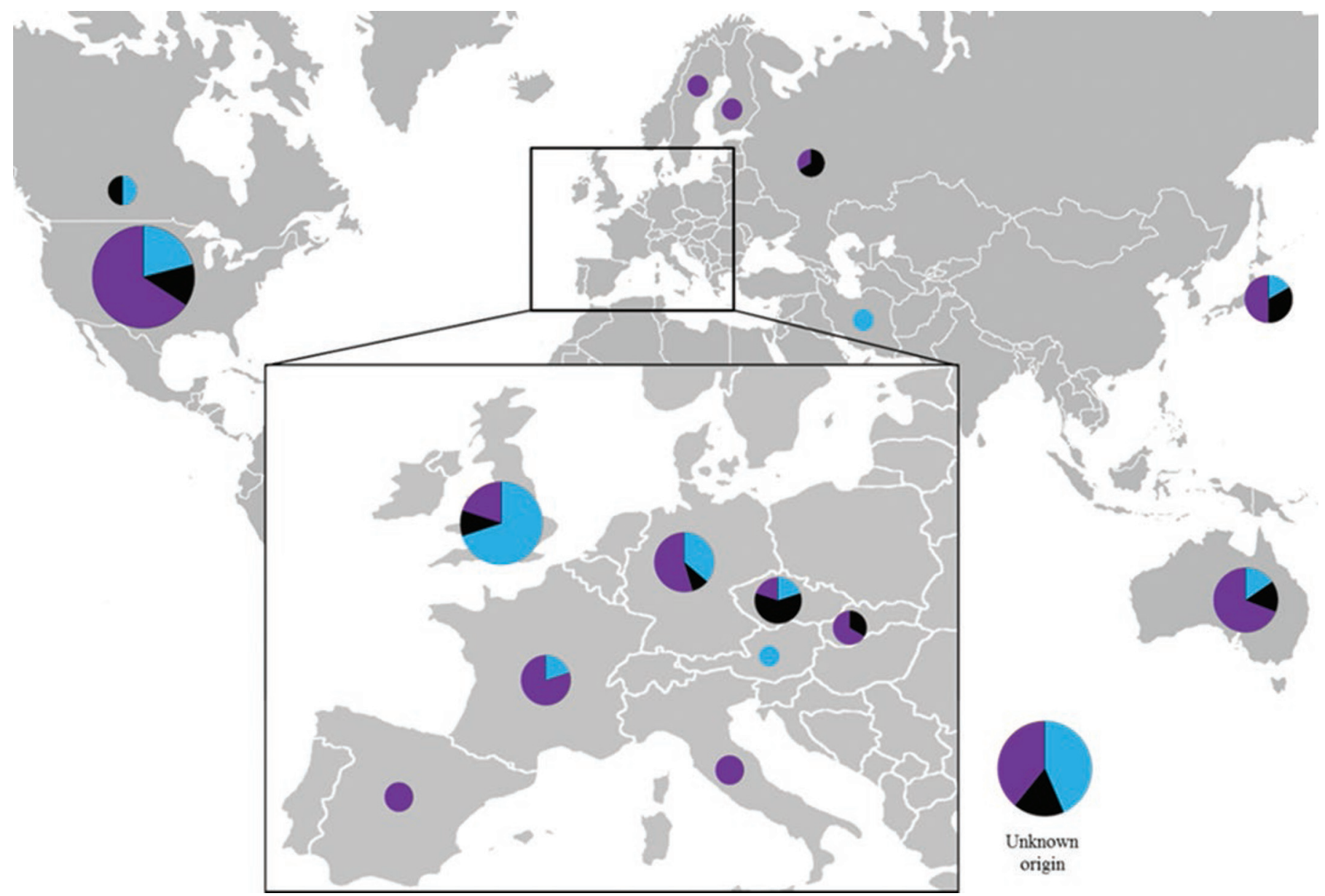

Figure 1. Geographical distribution of 137 lactococcal phages obtained from industrial collaborators. The size of individual pie charts is proportional to the number of phages isolated per country. Three distinct group phages were identified and differentiated: light gray $($ blue $)=$ P335 group; black = c2 group; dark gray $($ purple $)=936$ group. Color version available online.

of each host within the collection of 113 strains was determined by an established multiplex PCR method (Mahony et al., 2013; Table 5). The obtained results reveal that our Lc. lactis collection harbored most strains possessing a type C CWPS genotype (57.52\%; 65 strains out of 113), with smaller proportions possessing the type A or U (unknown) CWPS genotype (22 and 18 strains out of 113 or 19.47 and $15.93 \%$, respectively). Additionally, just 8 out of 113 strains exhibited the type B CWPS genotype (7.08\%; Table 5). Finally, possible CWPS-phage preference correlations were assessed based on the obtained data from the phage-host survey (Table 5 and Supplemental Tables S1, S2, and S3; https://doi.org/10.3168/jds.2017-13403). Based on this information, it appears that phages belonging to the 936 group exhibit an infection preference for lactococcal strains possessing CWPS type C (Table 5) as 40 of the 65 lactococcal strains that were susceptible to the 936 phages were characterized as CWPS type C
(61.54\%; Table 5). In contrast, P335 phages exhibit a high preference for CWPS-type A strains with almost half of the 25 lactococcal P335 host strains possessing CWPS type A. Interestingly, c2-group phages, which are known to use a proteinaceous receptor (Valyasevi et al., 1991; Monteville et al., 1994; Mahony and van Sinderen, 2012; Millen and Romero, 2016), appear to have a host preference for the CWPS type C (Table 5) with almost three-quarters of the 42 host strains identified belonging to the type C CWPS (71.43\%; Table 5$)$.

\section{Assessment of Individual Phage Genomes by Restriction Profile Analysis}

To explore the genetic diversity among individual members of the 3 phage groups (as assigned in the previous section), endonuclease restriction profiling (using EcoRV and EcoRI) of genomic DNA of the 137 phage isolates was carried out. The resulting restriction pro- 
Table 4. Phage-host range of 137 lactococcal phages against 113 lactococcal strains

\begin{tabular}{lccc}
\hline $\begin{array}{l}\text { Phage } \\
\text { group }\end{array}$ & $\begin{array}{c}\text { No. of } \\
\text { phages }\end{array}$ & $\begin{array}{c}\text { Total strains infected } \\
\text { (out of 113) }\end{array}$ & $\begin{array}{c}\text { Average number of strains } \\
\text { infected per phage }\end{array}$ \\
\hline 936 & 84 & 65 & 2.48 \\
c2 & 21 & 42 & 9.09 \\
P335 & 32 & 25 & 4.47 \\
Total & 137 & & \\
\hline
\end{tabular}

Table 5. Determination of the Lactococcus lactis cell wall polysaccharide (CWPS) type and CWPS phage preference

\begin{tabular}{lccccc}
\hline & \multicolumn{2}{c}{ No. (\%) of lactococcal hosts (CWPS types) infected } & \multicolumn{1}{c}{$\begin{array}{c}\text { No. of } \\
\text { strains }\end{array}$} \\
\cline { 2 - 5 } Phage group & $\mathrm{A}$ & $\mathrm{B}$ & $\mathrm{C}$ & Unknown (U) & \\
\hline 936 & $2(6.44)$ & $1(3.23)$ & $20(64.52)$ & $8(25.81)$ & $31(27.43)$ \\
c2 & $1(5.88)$ & $1(5.88)$ & $13(76.47)$ & $2(11.77)$ & $17(15.04)$ \\
P335 & $5(45.46)$ & 0 & $2(18.18)$ & $4(36.36)$ & $11(9.74)$ \\
$936+$ c2 & $3(15)$ & $2(10)$ & $15(75)$ & 0 & $20(17.70)$ \\
$936+$ P335 & $4(44.45)$ & 0 & $3(33.33)$ & $2(22.22)$ & $9(7.96)$ \\
$936+$ c2 + P335 & $2(40)$ & 0 & $2(40)$ & $1(20)$ & $5(4.43)$ \\
None & $5(25)$ & $4(20)$ & $10(50)$ & $1(5)$ & $20(17.70)$ \\
No. of strains & $22(19.47)$ & $8(7.08)$ & $65(57.52)$ & $18(15.93)$ & 113 \\
\hline
\end{tabular}
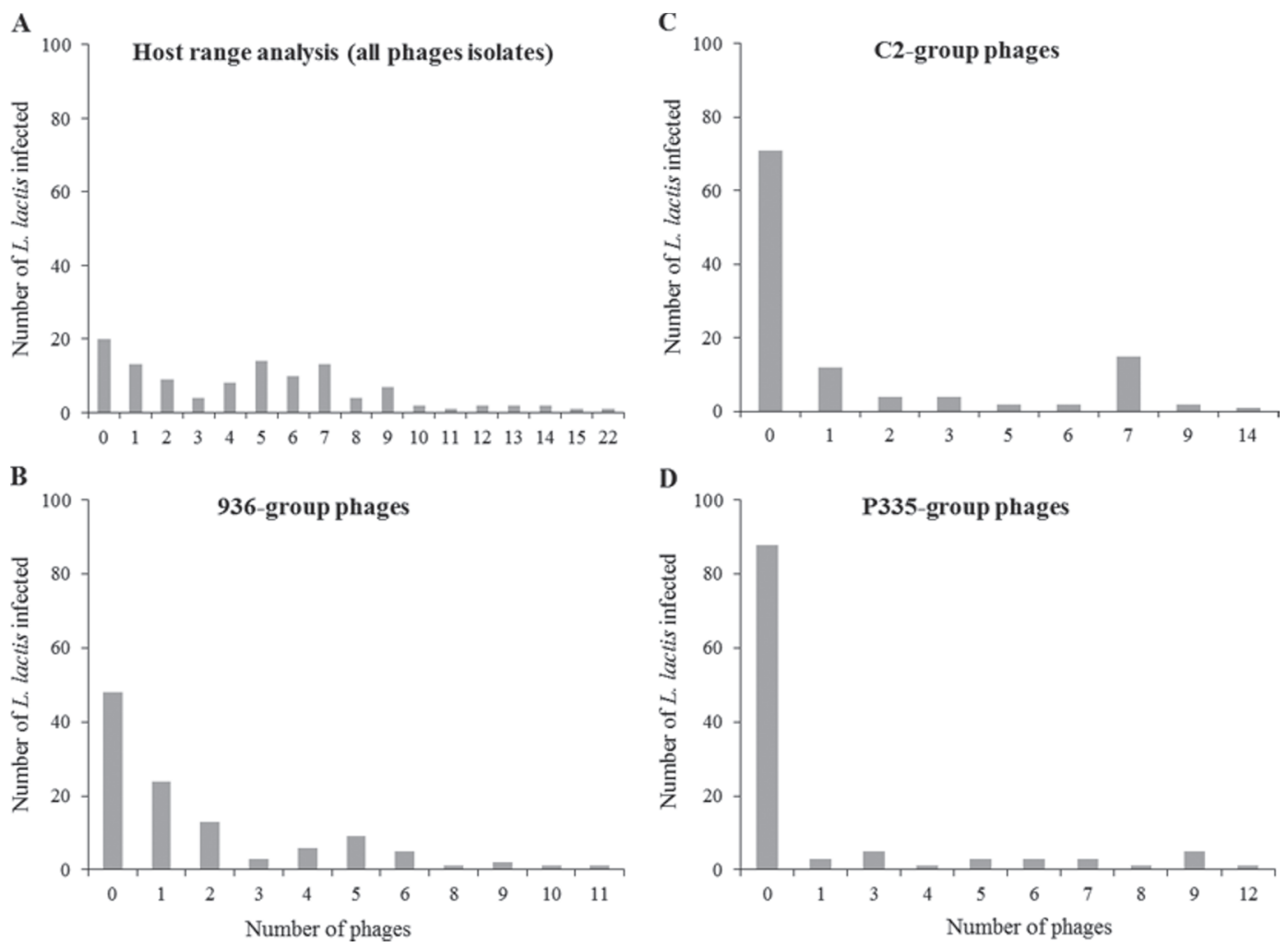

Figure 2. (A) Determination of the number of Lactococcus lactis strains susceptible to infection by members of the 3 main lactococcal phage groups (936, c2, and P335) isolated in this study. Representative susceptibility of 113 lactococcal strains to infection by (B) a collection of 84 isolated phages identified as belonging to the 936 group, (C) a collection of 21 isolated phages identified as belonging to the c2 group, and (D) a collection of 32 isolated phages identified as belonging to the P335 group. 
files were compared, resulting in the identification of 49 distinct restriction profiles among the 936-group phage isolates (out of 84 analyzed; representative profiles are presented in Figure 3). Using a similar approach, 21 distinct P335 phage genotypes and 12 distinct $\mathrm{c} 2$ phage genotypes were identified (out of 32 and 21 analyzed, respectively; Figure 4). Comparing the intra-group enzymatic restriction profiles and the (accumulated) sizes of generated restriction fragments, the genomes of the P335-group phages were observed to be the largest, followed in descending order by those of the 936 and c2 groups. The P335-group phages were shown to have a higher number of restriction sites than members of the 936 and $\mathrm{c} 2$ groups. Furthermore, the genome size of each phage was estimated based on the restriction profiles: 936-group isolates were estimated to have genome sizes in the range of 26 to $32 \mathrm{~kb}$, whereas those of P335group phages were estimated at 34 to $38 \mathrm{~kb}$. Finally, the $\mathrm{c} 2$-group genomes were concise, ranging between
20 and $22 \mathrm{~kb}$ (phage names and relevant information are provided in Supplemental Tables S1, S2, and S3; https://doi.org/10.3168/jds.2017-13403).

Several studies investigating phage biodiversity in dairy facilities have been performed and incorporate a vast array of geographical locations, including France (19 whey samples screened; Ly-Chatain et al., 2011), central Europe (156 whey samples; Murphy et al., 2013), Poland (33 whey samples; Szczepanska et al., 2007), Canada (28 whey samples; Bissonnette et al., 2000), and Republic of Belarus (160 whey samples; Raiski and Belyalsova, 2009). To the best of our knowledge, the present study is the largest (published) phage biodiversity screen of dairy facilities (more than 100,000 whey samples tested), incorporating whey samples from 16 distinct geographical locations. Our results revealed a very substantial level of diversity among the isolated Lc. lactis bacteriophages. As expected, and in agreement with previous studies (Bissonnette et al., 2000;
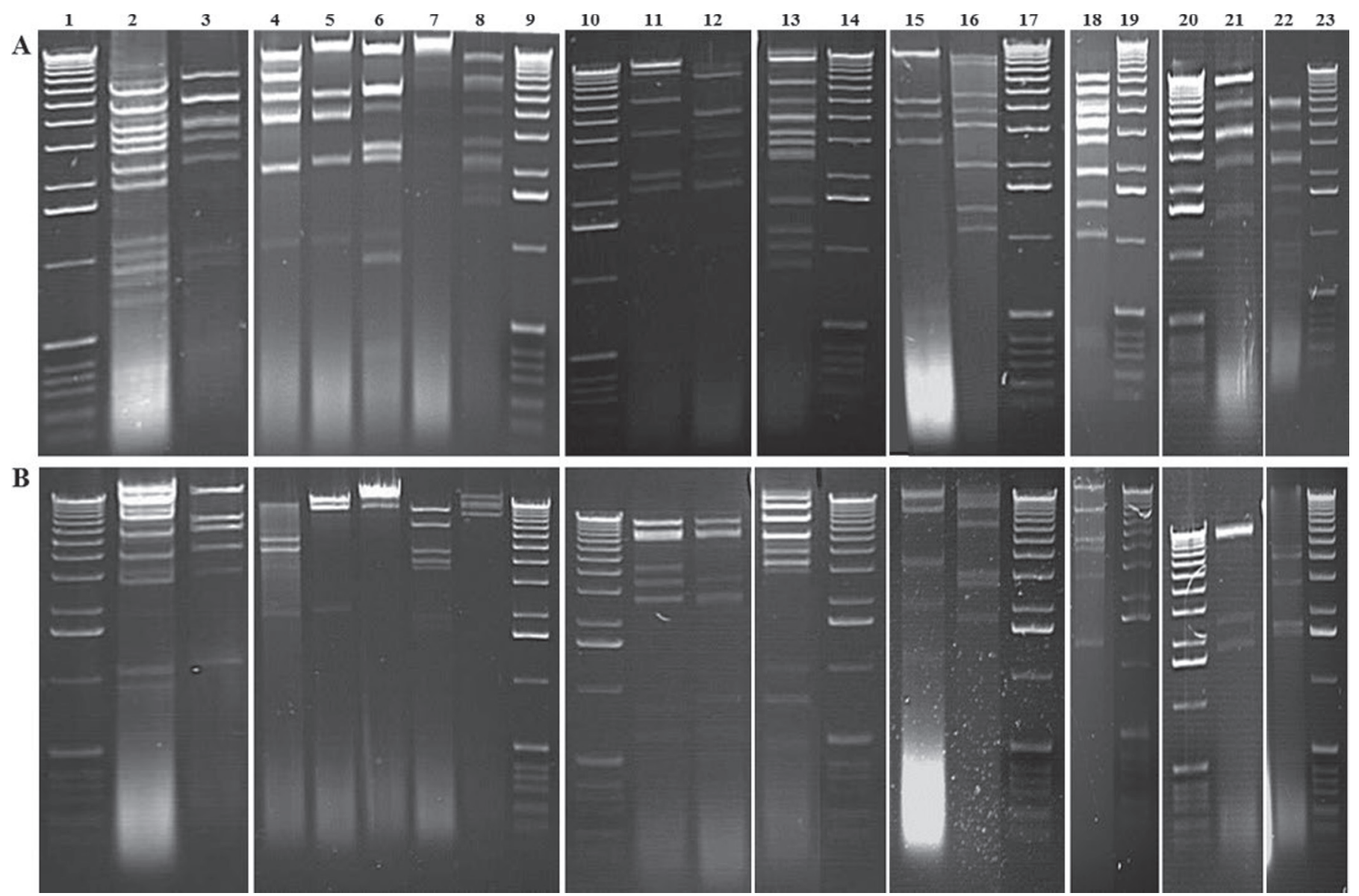

Figure 3. Representative restriction profiles of 936-group phages isolated from lactococcal industrial strains cut with $E c o$ RV (A) and $E c o$ RI (B). Lanes 1, 9, 10, 14, 17, 19, and $23=$ molecular weight marker X (Roche Diagnostic Corp., Indianapolis, IN); lanes 2 to $8=1$ lactococcal phages 56301, 56304, 96603, 96604, 96605, 79201, 63302, respectively; lanes 11 to 13 = lactococcal phages 62601, 62602, 62605, respectively; lanes 15 to $16=$ lactococcal phages 38507 and 38508, respectively; lane $18=$ lactococcal phage 30804 ; and lanes 21 and $22=$ lactococcal phages 56001 and 05601 , respectively. Lane 20 is also a molecular weight marker for sample no. 21. 

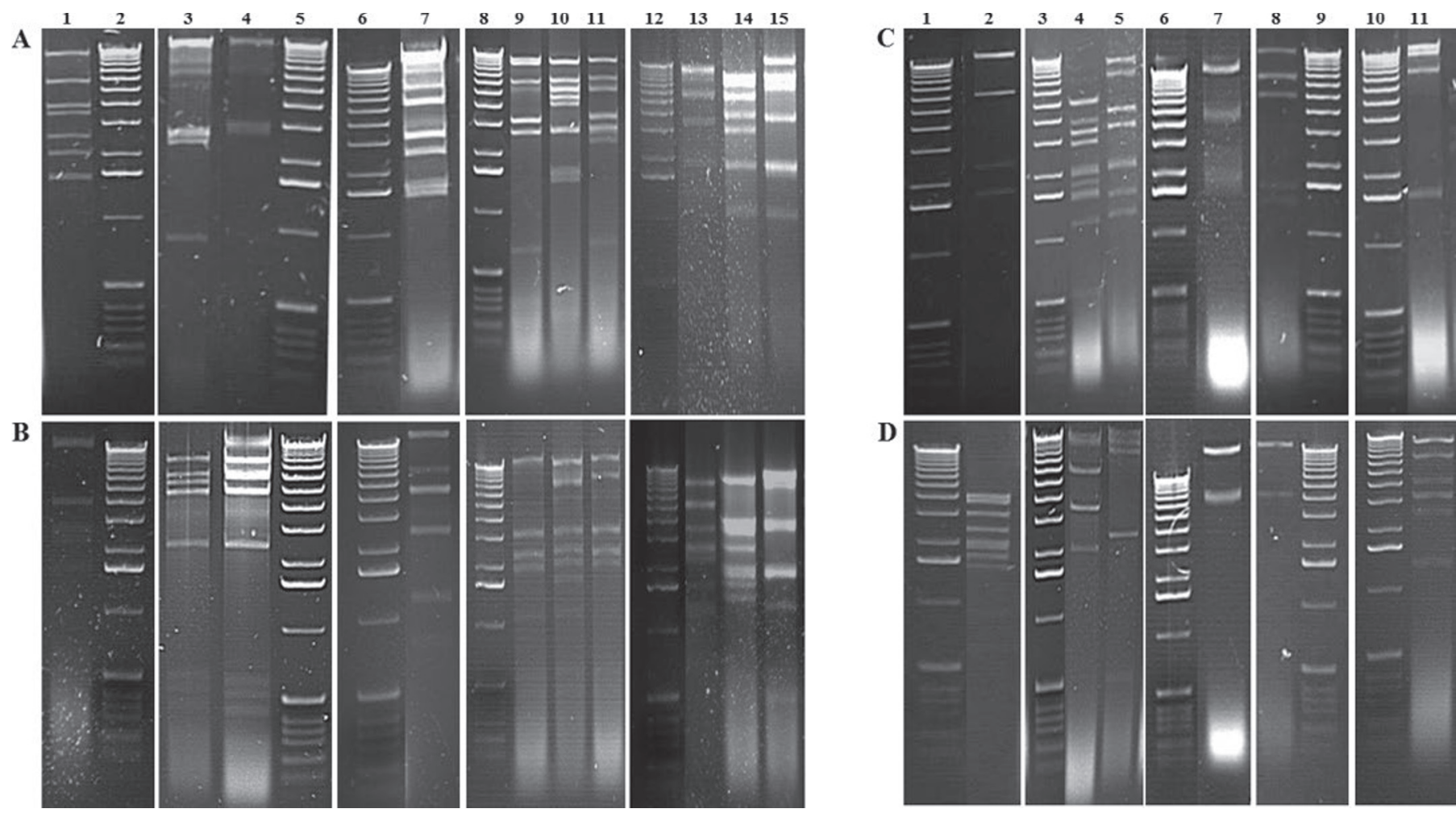

Figure 4. Representative restriction profiles of P335-group phages isolated from lactococcal industrial strains cut with EcoRV (A) and EcoRI (B). Lanes 2, 5, 6, 8, and $12=$ molecular weight marker X (Roche Diagnostic Corp., Indianapolis, IN); lane $1=$ lactococcal phage 38502; lanes 3 and 4 = lactococcal phages 98102 and 98101 , respectively; lane $7=$ lactococcal phage 62502 ; lane 12 in panel A and B is a molecular weight marker. Lanes 9 to 11 = lactococcal phages 53801, 53802, and 39001, respectively. Lanes 13 to $15=$ lactococcal phages 98204,98205 , and 98202 respectively. Representative restriction profiles of c2-group phages isolated from lactococcal industrial strains cut with $E c o R V(C)$ and $E c o R I$ (D). Lanes 1, 3, 6, 9, and $10=$ molecular weight marker X (Roche Diagnostic Corp.); lane 2 = lactococcal phage 62606 ; lanes 4 and $5=$ lactococcal phages 62401 and 62402 , respectively; lanes 7 and $8=$ lactococcal phages 56006 and 37203 , respectively; lane $11=$ lactococcal phage 60303 .

Madera et al., 2004; Mahony et al., 2013; Murphy et al., 2013), 936-group phages were isolated most frequently, followed by members of the P335 and c2 groups. In the present study, a phage-host survey involving more than 15,000 possible phage-host combinations was undertaken, highlighting the relatively broad host range of the $\mathrm{c} 2$ phages compared with the other phage group isolates. This is in agreement with a previous study in Poland, where $41 \%$ of the c2 phage isolates infected more than 2 strains, whereas phages of the 936 group typically infected a single strain (Szczepanska et al., 2007). The P335-group phages isolated in the present study had a broader host range than the 936-group phage isolates, which is in contrast to the narrow host range typically reported for members of this group. The source of the phages that colonize dairy environments has not yet been fully established and, once colonized within the processing environment, they are difficult to eliminate. In addition to resident phage populations, it is possible that phages enter the plant via the incoming milk (McIntyre et al., 1991) or through the starter strains themselves as lysogens (P335) or pseudolysogens (c2 and 936) (Stadhouders and Leenders, 1984; Madera et al., 2004). Lactococcal strains harbor prophages that may become induced and produce progeny that can infect other strains in the starter blend (Chopin et al., 2001). For the 936 and P335 phages, interactions with the host cells are thought to be mediated by recognition between the phage receptor binding protein (RBP) and the host cell wall polysaccharides (Spinelli et al., 2006; Tremblay et al., 2006; Mahony and van Sinderen, 2012), whereas for the $\mathrm{c} 2$ phages, the saccharide recognition stage is not as well described (Monteville et al., 1994). The 936- and P335-group phages isolated in this study exhibited a preference to infect lactococcal strains belonging to CWPS types $\mathrm{C}$ and A, respectively. Interestingly, the $\mathrm{c} 2$-group phages presented with a wide host range composed primarily of host strains with a C-type CWPS, a potential correlation for the reversible interaction between $\mathrm{c} 2$ phages and the cell wall saccharidic structures.

The ability of different groups of lactococcal bacteriophages to recognize distinct and specific polysaccharides presented on the Lc. lactis cell surface makes 
lactococcal phages an excellent model for molecular studies on phage-host interactions. This study presents a global perspective of dairy phage biodiversity and highlights the value of phage screening (1) to obtain an overall distribution and diversity profile of bacteriophages worldwide, and (2) to provide comprehensive insights into the evolutionary basis for these problematic dairy lactococcal bacteriophage members that may overcome starter rotations or resist bacterial anti-phage mechanisms.

In conclusion, virulent lactic acid bacteria phages still pose a serious threat to industrial fermentations, and several strategies have been introduced in a bid to control their numbers. Despite the array of measures to control this natural phenomenon, phages evolve and new variants continue to emerge. Variations in the host range might result either from phages bypassing phage resistance mechanisms or from the introduction of starter cultures into rotations.

Here, we report the identification of a large collection of novel lactococcal dairy phages, which may provide the foundation for continuing studies related to the specific interactions of these intriguing phages and their sensitive hosts. Our study has highlighted the importance of having complete information regarding the type of starter culture used, the operation type (i.e., modern controlled operation versus traditional production practice), and phage isolation and distribution for future biodiversity studies using dairy phages. Ultimately, this may improve processes of lactic acid bacteria starter strain selection, thus minimizing the risk of phage proliferation in industrial environments.

\section{ACKNOWLEDGMENTS}

This work was supported by the Science Foundation Ireland (SFI, Ireland). Joana Oliveira is funded by DSM Food Specialties, and Laurens Hanemaaijer and Thijs Kouwen are employees of DSM Food Specialties. Jennifer Mahony is the recipient of a Starting Investigator Research Grant (SIRG; Ref. No. 15/SIRG/3430) funded by SFI. Douwe van Sinderen is supported by a Principal Investigator Award (ref. no. 13/IA/1953) through SFI.

\section{REFERENCES}

Ainsworth, S., I. Sadovskaya, E. Vinogradov, P. Courtin, Y. Guerardel, J. Mahony, T. Grard, C. Cambillau, M. P. Chapot-Chartier, and D. van Sinderen. 2014a. Differences in lactococcal cell wall polysaccharide structure are major determining factors in bacteriophage sensitivity. MBio 5:e00880-14. https://doi.org/10.1128/ mBio.00880-14.

Ainsworth, S., S. Stockdale, F. Bottacini, J. Mahony, and D. van Sinderen. 2014b. The Lactococcus lactis plasmidome: Much learnt, yet still lots to discover. FEMS Microbiol. Rev. 38:1066-1088.
Bissonnette, F., S. Labrie, H. Deveau, M. Lamoureux, and S. Moineau. 2000. Characterization of mesophilic mixed starter cultures used for the manufacture of aged cheddar cheese. J. Dairy Sci. 83:620627.

Chapot-Chartier, M. P., E. Vinogradov, I. Sadovskaya, G. Andre, M. Y. Mistou, P. Trieu-Cuot, S. Furlan, E. Bidnenko, P. Courtin, C. Pechoux, P. Hols, Y. F. Dufrene, and S. Kulakauskas. 2010. Cell surface of Lactococcus lactis is covered by a protective polysaccharide pellicle. J. Biol. Chem. 285:10464-10471.

Chopin, A., A. Bolotin, A. Sorokin, S. D. Ehrlich, and M. C. Chopin. 2001. Analysis of six prophages in Lactococcus lactis IL1403: Different genetic structure of temperate and virulent phage populations. Nucleic Acids Res. 29:644-651.

Crutz-Le Coq, A. M., B. Cesselin, J. Commissaire, and J. Anba. 2002. Sequence analysis of the lactococcal bacteriophage bIL170: Insights into structural proteins and $\mathrm{HNH}$ endonucleases in dairy phages. Microbiology 148:985-1001.

del Rio, B., A. G. Binetti, M. C. Martin, M. Fernandez, A. H. Magadan, and M. A. Alvarez. 2007. Multiplex PCR for the detection and identification of dairy bacteriophages in milk. Food Microbiol. 24:75-81.

Deng, Y. M., C. Q. Liu, and N. W. Dunn. 2000. LldI, a plasmidencoded type I restriction and modification system in Lactococcus lactis. DNA Seq. 11:239-245.

Deveau, H., S. J. Labrie, M. C. Chopin, and S. Moineau. 2006. Biodiversity and classification of lactococcal phages. Appl. Environ. Microbiol. 72:4338-4346.

Dupont, K., F. K. Vogensen, H. Neve, J. Bresciani, and J. Josephsen. 2004. Identification of the receptor-binding protein in 936-species lactococcal bacteriophages. Appl. Environ. Microbiol. 70:58185824 .

Emond, E., B. J. Holler, I. Boucher, P. A. Vandenbergh, E. R. Vedamuthu, J. K. Kondo, and S. Moineau. 1997. Phenotypic and genetic characterization of the bacteriophage abortive infection mechanism AbiK from Lactococcus lactis. Appl. Environ. Microbiol. 63:1274-1283.

Farenc, C., S. Spinelli, E. Vinogradov, D. Tremblay, S. Blangy, I. Sadovskaya, S. Moineau, and C. Cambillau. 2014. Molecular insights on the recognition of a Lactococcus lactis cell wall pellicle by the phage 1358 receptor binding protein. J. Virol. 88:7005-7015.

Garneau, J. E., and S. Moineau. 2011. Bacteriophages of lactic acid bacteria and their impact on milk fermentations. Microb. Cell Fact. 10(Suppl. 1):S20.

Kleppen, H. P., T. Bang, I. F. Nes, and H. Holo. 2011. Bacteriophages in milk fermentations: Diversity fluctuations of normal and failed fermentations. Int. Dairy J. 21:592-600.

Labrie, S., and S. Moineau. 2000. Multiplex PCR for detection and identification of lactococcal bacteriophages. Appl. Environ. Microbiol. 66:987-994.

Labrie, S. J., J. Josephsen, H. Neve, F. K. Vogensen, and S. Moineau. 2008. Morphology, genome sequence, and structural proteome of type phage P335 from Lactococcus lactis. Appl. Environ. Microbiol. 74:4636-4644.

Labrie, S. J., J. E. Samson, and S. Moineau. 2010. Bacteriophage resistance mechanisms. Nat. Rev. Microbiol. 8:317-327.

Lillehaug, D. 1997. An improved plaque assay for poor plaque-producing temperate lactococcal bacteriophages. J. Appl. Microbiol. 83:85-90.

Lubbers, M. W., N. R. Waterfield, T. P. Beresford, R. W. Le Page, and A. W. Jarvis. 1995. Sequencing and analysis of the prolateheaded lactococcal bacteriophage $\mathrm{c} 2$ genome and identification of the structural genes. Appl. Environ. Microbiol. 61:4348-4356.

Ly-Chatain, M. H., L. Durand, V. Rigobello, A. Vera, and Y. Demarigny. 2011. Direct quantitative detection and identification of lactococcal bacteriophages from milk and whey by real-time PCR: Application for the detection of lactococcal bacteriophages in goat's raw milk whey in France. Int. J. Microbiol. 2011:594369.

Madera, C., C. Monjardin, and J. E. Suarez. 2004. Milk contamination and resistance to processing conditions determine the fate of $L a c$ tococcus lactis bacteriophages in dairies. Appl. Environ. Microbiol. 70:7365-7371. 
Mahony, J., F. Bottacini, D. van Sinderen, and G. F. Fitzgerald. 2014. Progress in lactic acid bacterial phage research. Microb. Cell Fact. 13(Suppl. 1):S1.

Mahony, J., H. Deveau, S. Mc Grath, M. Ventura, C. Canchaya, S. Moineau, G. F. Fitzgerald, and D. van Sinderen. 2006. Sequence and comparative genomic analysis of lactococcal bacteriophages jj50, 712 and P008: evolutionary insights into the 936 phage species. FEMS Microbiol. Lett. 261:253-261.

Mahony, J., W. Kot, J. Murphy, S. Ainsworth, H. Neve, L. H. Hansen, K. J. Heller, S. J. Sorensen, K. Hammer, C. Cambillau, F. K. Vogensen, and D. van Sinderen. 2013. Investigation of the relationship between lactococcal host cell wall polysaccharide genotype and 936 phage receptor binding protein phylogeny. Appl. Environ. Microbiol. 79:4385-4392.

Mahony, J., J. Murphy, and D. van Sinderen. 2012. Lactococcal 936type phages and dairy fermentation problems: from detection to evolution and prevention. Front. Microbiol. 3:335.

Mahony, J., J. Oliveira, B. Collins, L. Hanemaaijer, G. A. Lugli, H. Neve, M. Ventura, T. R. Kouwen, C. Cambillau, and D. van Sinderen. 2017. Genetic and functional characterisation of the lactococcal P335 phage-host interactions. BMC Genomics 18:146.

Mahony, J., and D. van Sinderen. 2012. Structural aspects of the interaction of dairy phages with their host bacteria. Viruses 4:14101424.

Mahony, J., and D. van Sinderen. 2014. Current taxonomy of phages infecting lactic acid bacteria. Front. Microbiol. 5:7.

Marco, M. B., S. Moineau, and A. Quiberoni. 2012. Bacteriophages and dairy fermentations. Bacteriophage 2:149-158.

McIntyre, K., H. A. Heap, G. P. Davey, and G. K. Limsowtin. 1991. The distribution of lactococcal bacteriophage in the environment of a cheese manufacturing plant. Int. Dairy J. 1:183-197.

Millen, A. M., and D. A. Romero. 2016. Genetic determinants of lactococcal $\mathrm{C} 2$ viruses for host infection and their role in phage evolution. J. Gen. Virol. 97:1998-2007.

Mills, S., O. E. McAuliffe, A. Coffey, G. F. Fitzgerald, and R. P. Ross. 2006. Plasmids of lactococci- Genetic accessories or genetic necessities? FEMS Microbiol. Rev. 30:243-273.

Monteville, M. R., B. Ardestani, and B. L. Geller. 1994. Lactococcal bacteriophages require a host-cell wall carbohydrate and a plasmamembrane protein for adsorption and ejection of DNA. Appl. Environ. Microbiol. 60:3204-3211.
Murphy, J., F. Bottacini, J. Mahony, P. Kelleher, H. Neve, A. Zomer, A. Nauta, and D. van Sinderen. 2016. Comparative genomics and functional analysis of the 936 group of lactococcal Siphoviridae phages. Sci. Rep. 6:21345.

Murphy, J., J. Mahony, M. Bonestroo, A. Nauta, and D. van Sinderen. 2014. Impact of thermal and biocidal treatments on lactococcal 936-type phages. Int. Dairy J. 34:56-61.

Murphy, J., B. Royer, J. Mahony, L. Hoyles, K. Heller, H. Neve, M. Bonestroo, A. Nauta, and D. van Sinderen. 2013. Biodiversity of lactococcal bacteriophages isolated from 3 Gouda-type cheese-producing plants. J. Dairy Sci. 96:4945-4957.

Raiski, A., and N. Belyalsova. 2009. Biodiversity of Lactococcus lactis bacteriophages in the Republic of Belarus. Int. J. Food Microbiol. 130:1-5.

Schouler, C., S. D. Ehrlich, and M. C. Chopin. 1994. Sequence and organization of the lactococcal prolate-headed bIL67 phage genome. Microbiology 140:3061-3069.

Spinelli, S., V. Campanacci, S. Blangy, S. Moineau, M. Tegoni, and C. Cambillau. 2006. Modular structure of the receptor binding proteins of Lactococcus lactis phages-The RBP structure of the temperate phage TP901-1. J. Biol. Chem. 281:14256-14262.

Stadhouders, J., and G. J. M. Leenders. 1984. Spontaneously developed mixed-strain cheese starters - Their behavior towards phages and their use in the Dutch cheese industry. Neth. Milk Dairy J. $38: 157-181$

Stuer-Lauridsen, B., T. Janzen, J. Schnabl, and E. Johansen. 2003. Identification of the host determinant of two prolate-headed phages infecting Lactococcus lactis. Virology 309:10-17.

Szczepanska, A. K., M. S. Hejnowicz, P. Kolakowski, and J. Bardowski. 2007. Biodiversity of Lactococcus lactis bacteriophages in Polish dairy environment. Acta Biochim. Pol. 54:151-158.

Tremblay, D. M., M. Tegoni, S. Spinelli, V. Campanacci, S. Blangy, C. Huyghe, A. Desmyter, S. Labrie, S. Moineau, and C. Cambillau. 2006. Receptor-binding protein of Lactococcus lactis phages: Identification and characterization of the saccharide receptor-binding site. J. Bacteriol. 188:2400-2410.

Valyasevi, R., W. E. Sandine, and B. L. Geller. 1991. A membraneprotein is required for bacteriophage- $\mathrm{C} 2$ infection of Lactococcus lactis subsp lactis C2. J. Bacteriol. 173:6095-6100. 